\title{
Fabrication and Superhydrophobic Property of ZnO Micro/Nanocrystals via a Hydrothermal Route
}

\author{
Chunmei Xiao, ${ }^{1,2,3}$ Jing Yan, ${ }^{2}$ and Taohai $\mathrm{Li}^{2}$ \\ ${ }^{1}$ Quanzhou Normal University, Quanzhou, Fujian 362011, China \\ ${ }^{2}$ College of Chemistry, Key Lab of Environment Friendly Chemistry and Application in Ministry of Education, \\ Xiangtan University, Xiangtan 411105, China \\ ${ }^{3}$ Materials College of Huaqiao University, Xiamen, Fujian 361021, China
}

Correspondence should be addressed to Taohai Li; hnlth@xtu.edu.cn

Received 12 October 2013; Accepted 24 February 2014; Published 23 March 2014

Academic Editor: Yanbao Zhao

Copyright (C) 2014 Chunmei Xiao et al. This is an open access article distributed under the Creative Commons Attribution License, which permits unrestricted use, distribution, and reproduction in any medium, provided the original work is properly cited.

Superhydrophobic $\mathrm{ZnO}$ micro/nanocrystals were fabricated on a large scale using a facile one-pot hydrothermal process successfully. The morphologies and chemical composition of as-synthesized $\mathrm{ZnO}$ were investigated by the scanning electron microscope (SEM) and X-ray powder diffraction (XRD). The morphology of ZnO products changed from uniform size microrods to flower-like micronanostructures, when the temperature changed from $120^{\circ} \mathrm{C}$ to $180^{\circ} \mathrm{C}$. The morphology of $\mathrm{ZnO}$ was strongly affected by the $\mathrm{pH}$. The wettability of the as-synthesized $\mathrm{ZnO}$ micro/nanocrystals was studied by measuring water contact angle (CA). The largest static CA for water is $167^{\circ}$, which is closely related to both the $\mathrm{ZnO}$ micro/nanostructure and chemical modification. Furthermore, the as-prepared $\mathrm{ZnO}$ surface showed superhydrophobicity for some corrosive liquids such as basic and acidic aqueous solutions. The CAs of the surface modified with $\mathrm{ZnO}$ prepared at $160^{\circ} \mathrm{C}$ were over $155^{\circ}$ in the range of $\mathrm{pH}=1-13$.

\section{Introduction}

In the past decade, the synthesis of functional nanostructures and their important applications have attracted great concern [1-7]. Semiconductor oxide nanomaterials such as $\mathrm{ZnO}$, $\mathrm{Ga}_{2} \mathrm{O}_{3}, \mathrm{In}_{2} \mathrm{O}_{3}$, and $\mathrm{SnO}_{2}$ have become a hot research topic for their widely used applications in transparent conductive film, optoelectronic devices, and gas sensing [8-11]. Among them, $\mathrm{ZnO}$ attracted more interest for the applications in low voltage, light-emitting diodes and diode lasers [12], a solar cell [13], the photocatalyst [14], and so forth. Most of all, Fortunato et al. reported the Ga-doped $\mathrm{ZnO}$ films prepared by RF magnetron sputtering, which is the first report of exploiting the GZO [15].

Currently, many interesting $\mathrm{ZnO}$ nanostructures such as nanobelt, nanosheet, and nanobridge structures have been synthesized by oxide thermal evaporation manner [16-18]. $\mathrm{ZnO}$ nanowires and nanorods prepared by solvothermal method have also been reported [19-21]. Various techniques that synthesize $\mathrm{ZnO}$ nanostructures have been developed, where hydrothermal method is very attractive owing to their low cost, catalyst-free state, and scalable synthesis [22, 23]. However, toxic, hazardous, and expensive reagents such as amines were inevitably used during the solvothermal process. In this paper, we adopt a more energy saving hydrothermal method (the assisted hydrothermal route) to synthesize $\mathrm{ZnO}$ micro/nanomaterials at low temperature without any toxic, hazardous, and expensive reagents and demonstrate their potential superhydrophobic property of the rough surface that is constructed by $\mathrm{ZnO}$ micro/nanomaterials. The products were characterized by XRD and SEM. We suppose that this method of preparation of superhydrophobic surface of $\mathrm{ZnO}$ may provide guidance for the preparation of other functional inorganic materials.

\section{Experimental}

2.1. Synthesis. All the chemicals used for synthesis of the $\mathrm{ZnO}$ were of analytical grade and used as received without any further purification. Growth of $\mathrm{ZnO}$ micro/nanocrystals was performed by a PEG1000 assisted hydrothermal method. 


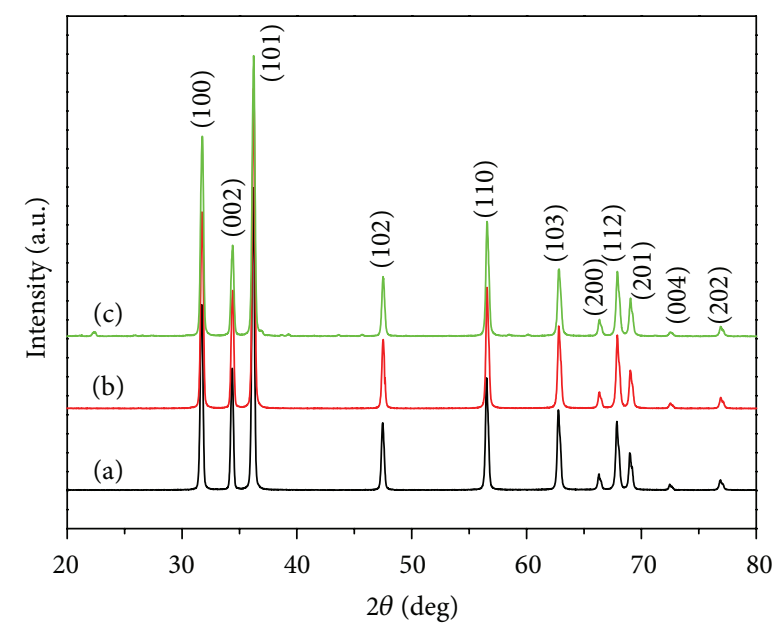

FIGURE 1: XRD patterns of $\mathrm{ZnO}$ samples prepared at different temperatures: (a) $120^{\circ} \mathrm{C}$, (b) $160^{\circ} \mathrm{C}$, and (c) $180^{\circ} \mathrm{C}$.

In a typical synthesis, $0.6 \mathrm{~g} \mathrm{Zn}\left(\mathrm{CH}_{3} \mathrm{COO}\right)_{2} \cdot 2 \mathrm{H}_{2} \mathrm{O}$ was added to $6 \mathrm{~mL}$ deionized water to form precursor solution, and $10 \mathrm{~mL} \mathrm{NaOH}$ solution was added into above solution with stirring to form white suspension. Then, 0.1 g PEG1000 was added to the white suspension. After stirring for $30 \mathrm{~min}$ at room temperature, adjust the $\mathrm{pH}$ value of the solution to 8 with $1 \mathrm{~mol} / \mathrm{L}$ of $\mathrm{HCl}$ solution. The mixture was transferred to and sealed in a teflon-lined autoclave; the autoclave was sealed and maintained at $140^{\circ} \mathrm{C}$ for $24 \mathrm{~h}$. The products were spontaneously cooled to room temperature in the furnace to get the $\mathrm{ZnO}$ micro/nanomaterials samples. The products were collected by centrifugation and washed with deionized water and absolute alcohol. The final samples were obtained after drying at $60^{\circ} \mathrm{C}$ for $12 \mathrm{~h}$ in vacuum. With a similar procedure, the other samples were prepared by adjusting the $\mathrm{pH}$ values of the solution to 10 and 12 with $\mathrm{HCl}$ solution, respectively. Then, we study the characterization of the $\mathrm{ZnO}$.

2.2. Characterization. The morphologies of $\mathrm{ZnO}$ samples were characterized by scanning electron microscopy (SEM, JSM-6700F). The phase analysis was performed by X-ray diffractometer (XRD). The XRD patterns were measured on a MiniFlex2 goniometer, employing a scanning rate of $0.02^{\circ} \mathrm{s}^{-1}$ in the $2 \theta$ range from $5^{\circ}$ to $70^{\circ}$, and the operating voltage and current were maintained at $30 \mathrm{kV}$ and $15 \mathrm{~mA}$, respectively. Water contact angle (CA) and sliding angle measurements were carried out by using a Model $250(\mathrm{p} / \mathrm{n}$ 250-F1) goniometer (ramé-hart instrument Co, USA) at ambient temperature. Water droplets $(5 \mathrm{uL})$ were carefully dropped onto the surfaces, and the average value of five measurements obtained at different positions in the samples was used as the final contact angle.

\section{Results and Discussion}

XRD was used to characterize the crystalline phase and purity of the sample. Figure 1 shows the XRD patterns of the assynthesized $\mathrm{ZnO}$ products prepared at different temperature.

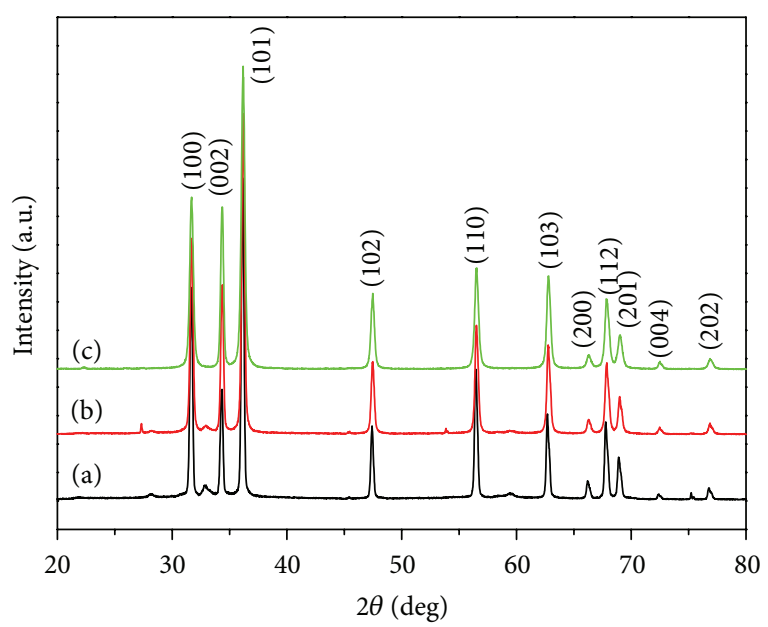

FIgURE 2: XRD patterns of $\mathrm{ZnO}$ samples prepared at $120^{\circ} \mathrm{C}$ with different $\mathrm{pH}$ values: (a) $\mathrm{pH}=8$, (b) $\mathrm{pH}=10$, and (c) $\mathrm{pH}=12$.

All diffraction peaks are in good agreement with those in the JCPDS Card no. 36-1451. The indexed diffraction peaks can be ascribed to $\mathrm{ZnO}$ with a pure wurtzite structure [23] and lattice constants of $a=3.250 \AA, b=3.250 \AA$, and $c=5.207 \AA$. No diffraction peaks of impurities are observed, indicating that the pure $\mathrm{ZnO}$ micro/nanocrystals can be obtained by this method. As showed in Figure 1, the diffraction peak intensity and the half-peak width of $\mathrm{ZnO}$ prepared at different temperatures are comparable, which indicates that the reaction temperature has little effect on the crystallinity of $\mathrm{ZnO}$.

The XRD patterns of the as-synthesized $\mathrm{ZnO}$ products at different $\mathrm{pH}$ values are shown in Figure 2. All diffraction peaks are in good agreement with those in the JCPDS Card no. 36-1451. The indexed diffraction peaks can be ascribed to $\mathrm{ZnO}$ with a pure wurtzite structure [24] and lattice constants of $a=3.250 \AA, b=3.250 \AA$, and $c=5.207 \AA$. No diffraction peaks of impurities are observed. The strong peak intensity of (002) revealed that the $\mathrm{ZnO}$ nanorods grew along the (001) direction [25]. As shown in Figure 2, the diffraction peak intensity and the half-peak width of $\mathrm{ZnO}$ prepared at different $\mathrm{pH}$ values are similar, which indicates that the $\mathrm{pH}$ has little effect on the crystallinity of $\mathrm{ZnO}$. Thus, $\mathrm{ZnO}$ can be synthesized in a wide $\mathrm{pH}$ range.

SEM images of the as-synthesized $\mathrm{ZnO}$ products prepared at different temperatures are shown in Figure 3. As showed in Figure 3, when the reaction temperature was $120^{\circ} \mathrm{C}, \mathrm{ZnO}$ products mainly consisted of uniform size microrods with the mean particle size of $6 \mu \mathrm{m}$ (Figure 3(a)). With the increasing of the reaction temperature, $\mathrm{ZnO}$ nanorods appeared in the products (Figure $3(\mathrm{~b})$ ) and the microrods became shorter with the lengths of about $4 \mu \mathrm{m}$. When the reaction temperature was increased to $180^{\circ} \mathrm{C}$, more $\mathrm{ZnO}$ nanorods were observed and formed flower-like micro/nanostructures (Figure 3(c)). The results suggested that the reaction temperature has an important influence on the morphology of the $\mathrm{ZnO}$. Therefore, the changing of 


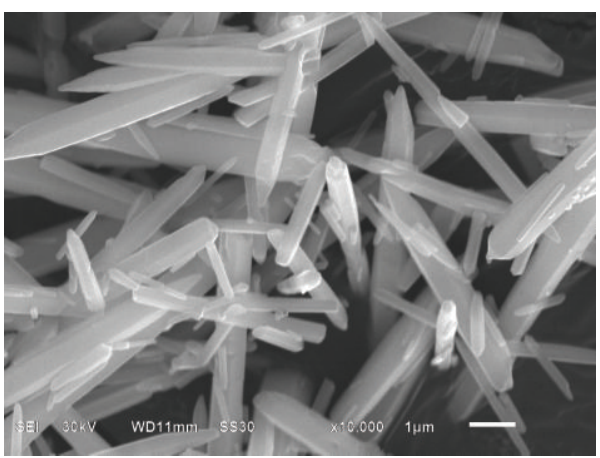

(a)

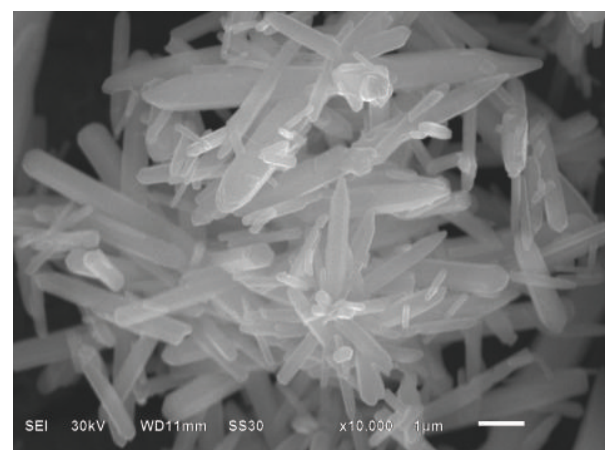

(b)

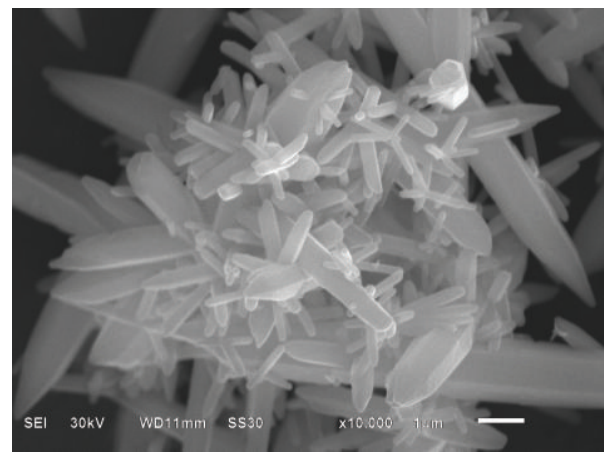

(c)

FIGURE 3: SEM images of ZnO samples prepared at different temperatures: (a) $120^{\circ} \mathrm{C}$, (b) $160^{\circ} \mathrm{C}$, and (c) $180^{\circ} \mathrm{C}$.

the reaction temperature can change the morphology of $\mathrm{ZnO}$ products.

The SEM images of the as-synthesized $\mathrm{ZnO}$ products prepared at different temperatures are shown in Figure 4. When the $\mathrm{pH}$ value of the reaction solution was 12 , morphology of the $\mathrm{ZnO}$ mainly consisted of uniform size composition leaves shaped nanosheets (Figure 4(c)). When the $\mathrm{pH}$ value of the reaction solution was $10, \mathrm{ZnO}$ products mainly consisted of uniform size nanorods with length of $5 \mu \mathrm{m}$ and the middle width of $200 \mathrm{~nm}$ in average (Figure 4(b)). When the reaction solution $\mathrm{pH}$ was decreased to 8 , most of the obtained products were uniform nanorods with the lengths of about 1$10 \mu \mathrm{m}$ and width of $120 \mathrm{~nm}$ in average as shown in Figure 4(a). Obviously, the $\mathrm{pH}$ value plays an important role in the morphological evolution of $\mathrm{ZnO}$ nanocrystals, especially in an alkaline environment. The decreasing of the $\mathrm{pH}$ value of reaction solution led to the formation of nanorods.

At the beginning of our experiment, $\mathrm{OH}^{-}$is first introduced into the solution of $\mathrm{Zn}^{2+}$, and $\mathrm{Zn}(\mathrm{OH})_{2}$ colloid is produced. $\mathrm{Zn}(\mathrm{OH})_{2}$ colloids can be decomposed into $\mathrm{Zn}^{2+}$ and $\mathrm{OH}^{-}$. When the concentrations of $\mathrm{Zn}^{2+}$ and $\mathrm{OH}^{-}$reach saturation, $\mathrm{ZnO}$ will be generated. There is a dissolution equilibrium between $\left[\mathrm{Zn}(\mathrm{OH})_{4}\right]^{2-}$ and $\mathrm{Zn}(\mathrm{OH})_{2}$. With increasing the concentration of $\mathrm{OH}^{-},\left[\mathrm{Zn}(\mathrm{OH})_{4}\right]^{2-}$ will be obtained from the reaction of $\mathrm{Zn}(\mathrm{OH})_{2}$ and $\mathrm{OH}^{-}$. With increasing the concentration of $\mathrm{Zn}^{2+}$ in the solution, the reverse reaction of $\left[\mathrm{Zn}(\mathrm{OH})_{4}\right]^{2-}$ will produce $\mathrm{Zn}(\mathrm{OH})_{2}$, and $\mathrm{ZnO}$ will be obtained finally

$$
\begin{gathered}
\mathrm{Zn}^{2+}+2 \mathrm{OH}^{-} \longleftrightarrow \mathrm{Zn}(\mathrm{OH})_{2} \\
\mathrm{Zn}(\mathrm{OH})_{2} \longrightarrow \mathrm{Zn}^{2+}+2 \mathrm{OH}^{-} \\
\mathrm{Zn}^{2+}+2 \mathrm{OH}^{-} \longleftrightarrow \mathrm{ZnO} \downarrow+\mathrm{H}_{2} \mathrm{O} \\
\mathrm{Zn}(\mathrm{OH})_{2}+2 \mathrm{OH}^{-} \longleftrightarrow\left[\mathrm{Zn}(\mathrm{OH})_{4}\right]^{2-}
\end{gathered}
$$

The mechanism of this synthesis is not very clear yet, but, on the basis of the experimental results and observations, we propose a possible mechanism for the formation of the structure of $\mathrm{ZnO}$ obtained in our approach that is mainly caused by the effect of PEG1000. It is generally believed that PEG1000 can be adsorbed on the surface of $\mathrm{ZnO}$ material. When PEG1000 was adsorbed by $\mathrm{ZnO}$ surface, the activity of $\mathrm{ZnO}$ nanostructures in certain areas of the surface will be inhibited, so the growth rate of $\mathrm{ZnO}$ nanostructures in some directions will slow down (Figure 5). Thus, PEG1000 adding $\mathrm{ZnO}$ nuclei will change the growth kinetics, leading to the formation of the crystal growth anisotropy $1 \mathrm{D} \mathrm{ZnO}$ nanostructures [26-28].

The corresponding surface wettability of the assynthesized samples was studied by measuring the water CA using a water droplet $(\mathrm{pH}=7)$ of $10 \mu \mathrm{L}$ (Figure 6). The CA 


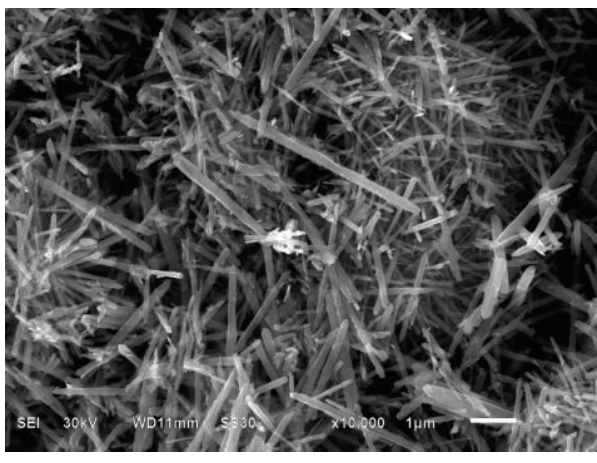

(a)

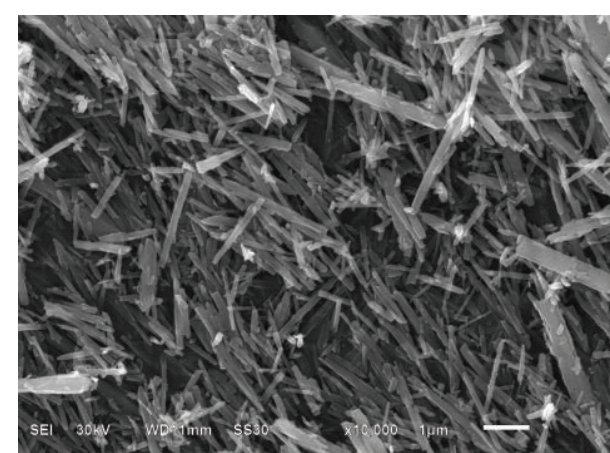

(b)

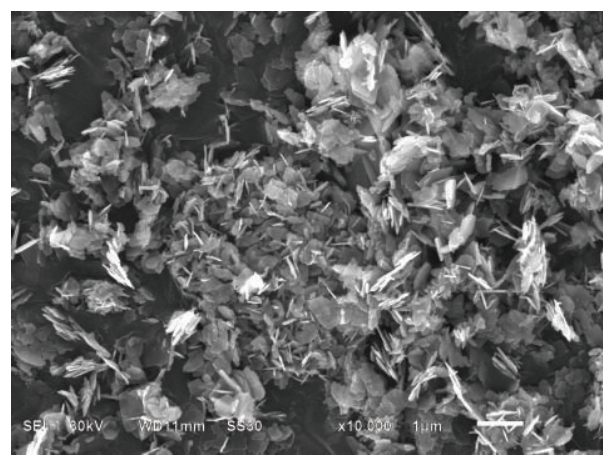

(c)

Figure 4: SEM images of $\mathrm{ZnO}$ samples prepared with different $\mathrm{pH}$ values: (a) $\mathrm{pH}=8$, (b) $\mathrm{pH}=10$, and (c) $\mathrm{pH}=12$.

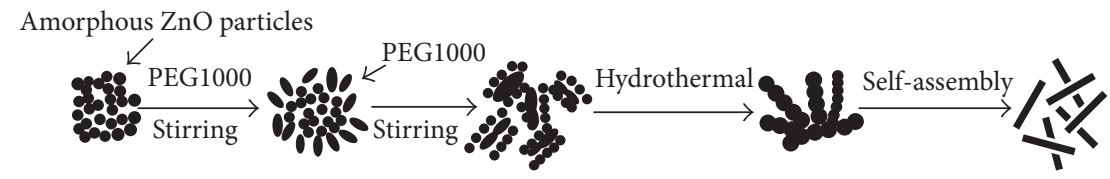

FIGURE 5: Illustration of the growth and self-assembly of the macro/nanorods.

values of the glass treated with as-synthesized samples doping with different amounts of methanol solution of $2 \%(\mathrm{v} / \mathrm{v})$ PFOTS were measured. It is well known that the solid surfaces with contact angles over $150^{\circ}$ are attributed to superhydrophobicity [29]. As showed in Figures 6(a)-6(c), the CA values of $\mathrm{ZnO}$ prepared at $120^{\circ} \mathrm{C}, 160^{\circ} \mathrm{C}$, and $180^{\circ} \mathrm{C}$ are $167^{\circ}, 163^{\circ}$, and $140^{\circ}$, respectively. In Figures $6(\mathrm{~d})-6(\mathrm{f})$, the CA values of $\mathrm{ZnO}$ prepared with $\mathrm{pH}$ values of 8,10 , and 12 are $160^{\circ}, 160^{\circ}$, and $161^{\circ}$, respectively. Experimental results show that the reaction temperature has an effect on the wetting property of $\mathrm{ZnO}$. With the increasing of the reaction temperature, the contact angle becomes smaller. When the reaction temperature is increased to $180^{\circ} \mathrm{C}, \mathrm{ZnO}$ structure rough surface does not have superhydrophobic properties. The $\mathrm{pH}$ value has little effect on the wetting property of $\mathrm{ZnO}$. In the range of $\mathrm{pH}=8-14$, rough surface constructed by $\mathrm{ZnO}$ has a superhydrophobic property.

Figure 7 shows the relationship between $\mathrm{pH}$ values of the water droplet and the $\mathrm{CA}$ on the $\mathrm{ZnO}$ superhydrophobic surfaces prepared at different temperature. The figure shows that static CAs of $\mathrm{ZnO}$ superhydrophobic surface prepared at $120^{\circ} \mathrm{C}$ were over $150^{\circ}$ in the range of $\mathrm{pH}$
= 3-13. The CAs of $\mathrm{ZnO}$ superhydrophobic surface prepared at $160^{\circ} \mathrm{C}$ were over $155^{\circ}$ in the range of $\mathrm{pH}=1-$ 13.

Figure 8 shows the relationship between $\mathrm{pH}$ values of the water droplet and $\mathrm{CA}$ on the $\mathrm{ZnO}$ superhydrophobic surfaces prepared at different $\mathrm{pH}$ values. The curves of contact angles of the modified surfaces at different $\mathrm{pH}$ values show similar law. The CA increases with the $\mathrm{pH}$ value firstly and then decreases slowly. Static contact angles of $\mathrm{ZnO}$ superhydrophobic surface prepared at different $\mathrm{pH}$ values are all over $150^{\circ}$.

\section{Conclusions}

In this work, $\mathrm{ZnO}$ micro/nanocrystals were synthesized by a simple hydrothermal method assisted by PEG1000. The samples show excellent superhydrophobic property at different reaction temperatures and $\mathrm{pH}$ values. The results show that the $\mathrm{ZnO}$ materials present long-term stability in the air as well as excellent resistance to corrosive liquids, including weak acidic and alkaline solutions. Therefore, this kind of 


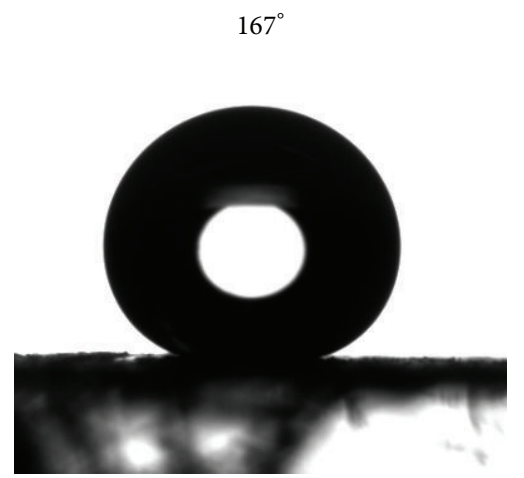

(a)

$160^{\circ}$

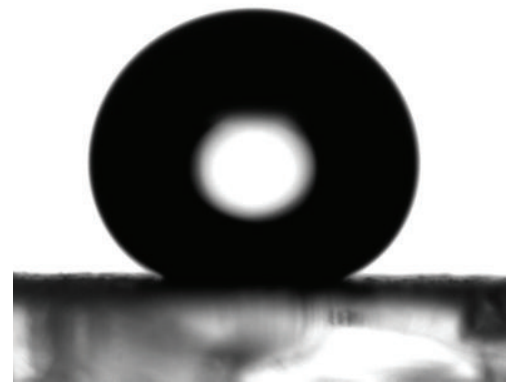

(d) $163^{\circ}$

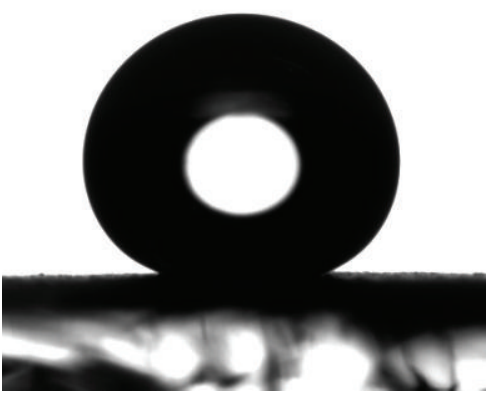

(b)

$160^{\circ}$

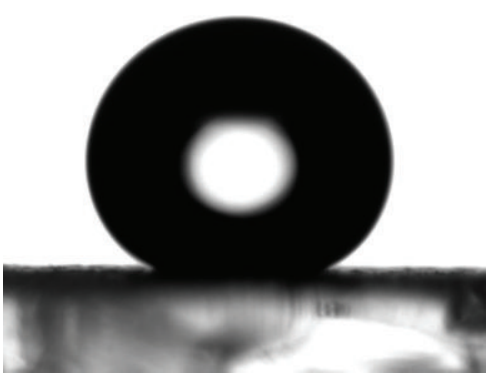

(e) $140^{\circ}$

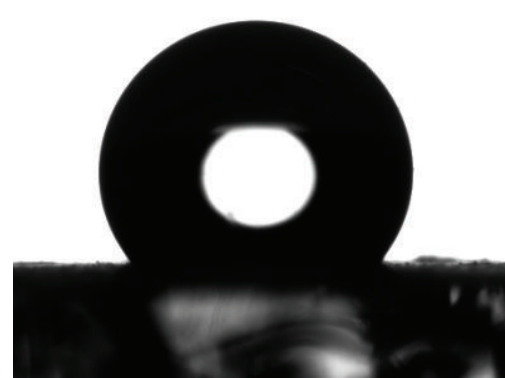

(c)

$161^{\circ}$

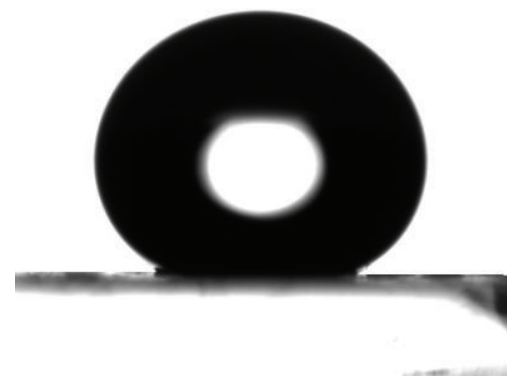

(f)

Figure 6: Wetting behavior of $\mathrm{ZnO}$ prepared at different temperatures: (a) $120^{\circ} \mathrm{C}$, (b) $160^{\circ} \mathrm{C}$, and (c) $180^{\circ} \mathrm{C}$, and at $120^{\circ} \mathrm{C}$ with different pH values: (d) $\mathrm{pH}=8,(\mathrm{e}) \mathrm{pH}=10$, and (f) $\mathrm{pH}=12$.

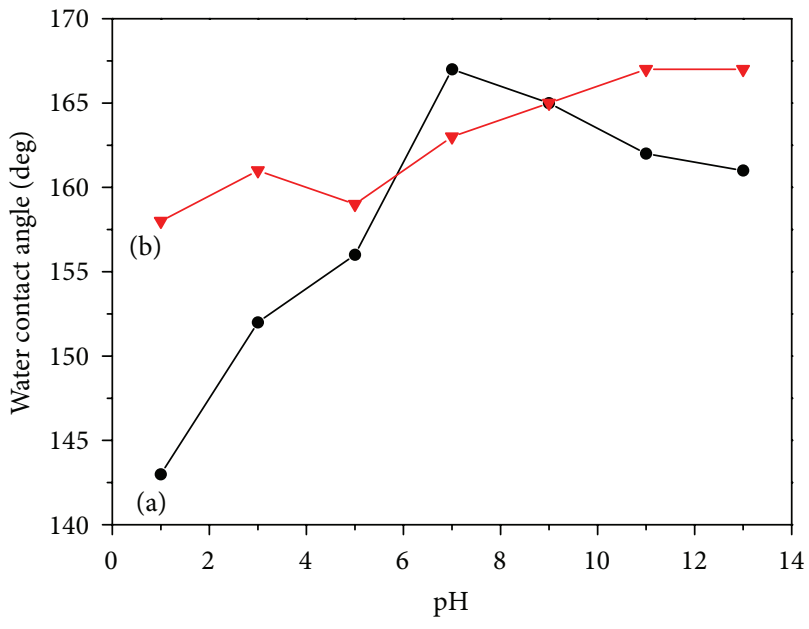

FIGURE 7: Water contact angles of the modified surface according to the $\mathrm{pH}$ of water droplet: $\mathrm{ZnO}$ prepared at (a) $120^{\circ} \mathrm{C}$ and (b) $160^{\circ} \mathrm{C}$.

material may be a promising substitute for the conventional engineering materials.

\section{Conflict of Interests}

The authors declare that there is no conflict of interests regarding the publication of this paper.

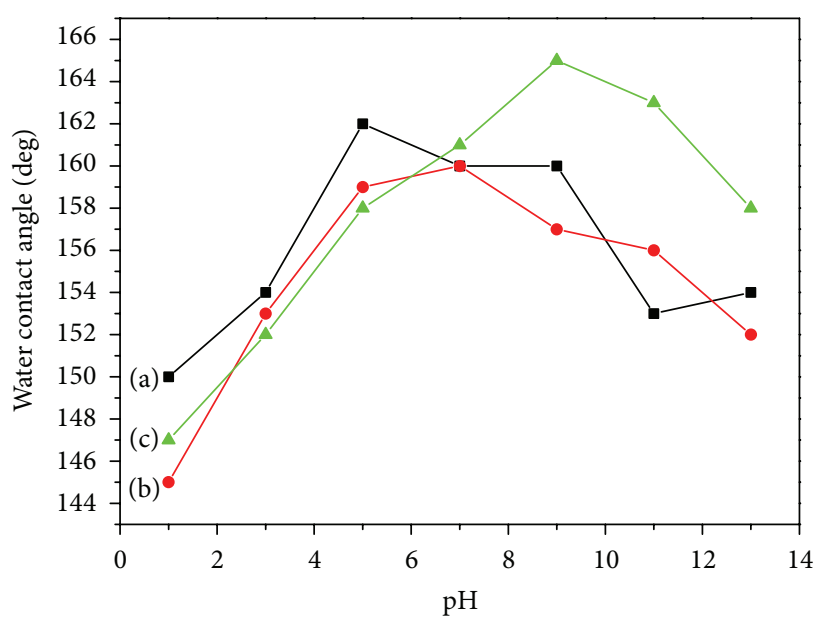

FIGURE 8: Water contact angles of the modified surface according to the $\mathrm{pH}$ of water droplet: $\mathrm{ZnO}$ prepared at $120^{\circ} \mathrm{C}$ with different $\mathrm{pH}$ values: (a) $\mathrm{pH}=8$, (b) $\mathrm{pH}=10$, and (c) $\mathrm{pH}=12$.

\section{Acknowledgments}

The authors acknowledge, with thanks, the financial support of a technology project of the Education Department of Fujian Province (JA12277), Fund of Quanzhou Technology Bureau (2012z119), Provincial Natural Science Foundation of 
Hunan, China (13JJ6041), and the National Natural Science Foundation of China (21343008).

\section{References}

[1] X. Duan, Y. Huang, R. Agarwal, and C. M. Lieber, "Singlenanowire elecctrically driven lasers," Nature, vol. 421, no. 6920, pp. 241-245, 2003.

[2] M. S. Fuhrer, J. Nygård, L. Shih et al., "Crossed nanotube junctions," Science, vol. 288, no. 5465, pp. 494-497, 2000.

[3] Z. F. Ren and Z. P. Huang, "Synthesis of large arrays of wellaligned carbon nanotubes on glass," Science, vol. 282, no. 5391, pp. 1105-1107, 1998.

[4] A. M. Morales and C. M. Lieber, "A laser ablation method for the synthesis of crystalline semiconductor nanowires," Science, vol. 279, no. 5348, pp. 208-211, 1998.

[5] H. Zhang, X. Ma, J. Xu, J. Niu, J. Sha, and D. Yang, "Directional CdS nanowires fabricated by chemical bath deposition," Journal of Crystal Growth, vol. 246, no. 1-2, pp. 108-112, 2002.

[6] W. Han, S. Fan, Q. Li, and Y. Hu, "Synthesis of gallium nitride nanorods through a carbon nanotube-confined reaction," Science, vol. 277, no. 5330, pp. 1287-1289, 1997.

[7] H. Zhang, X. Ma, Y. Ji, J. Xu, and D. Yang, "Single crystalline CdS nanorods fabricated by a novel hydrothermal method," Chemical Physics Letters, vol. 377, no. 5-6, pp. 654-657, 2003.

[8] D. S. Ginley and C. Bright, "Transparent conducting oxides," MRS Bulletin, vol. 25, no. 8, pp. 15-21, 2000.

[9] T. Aoki, Y. Hatanaka, and D. C. Look, "ZnO diode fabricated by excimer-laser doping," Applied Physics Letters, vol. 76, no. 22, pp. 3257-3258, 2000.

[10] G. Sberveglieri, S. Groppelli, P. Nelli, A. Tintinelli, and G. Giunta, "A novel method for the preparation of $\mathrm{NH}_{3}$ sensors based on ZnO-In thin films," Sensors and Actuators B: Chemical, vol. 25, no. 1-3, pp. 588-590, 1995.

[11] H. Ohta, K.-I. Kawamura, M. Orita, M. Hirano, N. Sarukura, and $\mathrm{H}$. Hosono, "Current injection emission from a transparent p-n junction composed of $\mathrm{p}-\mathrm{SrCu}_{2} \mathrm{O}_{2} / \mathrm{n}-\mathrm{ZnO}$," Applied Physics Letters, vol. 77, no. 4, pp. 475-477, 2000.

[12] E. M. Wong and P. C. Searson, "ZnO quantum particle thin films fabricated by electrophoretic deposition," Applied Physics Letters, vol. 74, no. 20, pp. 2939-2941, 1999.

[13] Y.-J. Lee, D. S. Ruby, D. W. Peters, B. B. McKenzie, and J. W. P. Hsu, " $\mathrm{ZnO}$ nanostructures as efficient antireflection layers in solar cells," Nano Letters, vol. 8, no. 5, pp. 1501-1505, 2008.

[14] X. Wang, Q. Zhang, Q. Wan, G. Dai, C. Zhou, and B. Zou, "Controllable $\mathrm{ZnO}$ architectures by ethanolamine-assisted hydrothermal reaction for enhanced photocatalytic activity," Journal of Physical Chemistry C, vol. 115, no. 6, pp. 2769-2775, 2011.

[15] E. Fortunato, A. Gonçalves, A. Marques et al., "New developments in gallium doped zinc oxide deposited on polymeric substrates by RF magnetron sputtering," Surface and Coatings Technology, vol. 180-181, pp. 20-25, 2004.

[16] J. Y. Lao, J. Y. Huang, D. Z. Wang, and Z. F. Ren, “ZnO nanobridges and nanonails," Nano Letters, vol. 3, no. 2, pp. 235238, 2003.

[17] C. Ye, G. Meng, Y. Wang, Z. Jiang, and L. Zhang, "On the growth of CdS nanowires by the evaporation of CdS nanopowders," Journal of Physical Chemistry B, vol. 106, no. 40, pp. 10338-10341, 2002.
[18] J. Y. Lao, J. G. Wen, and Z. F. Ren, "Hierarchical ZnO Nanostructures," Nano Letters, vol. 2, no. 11, pp. 1287-1291, 2002.

[19] C. Pacholski, A. Kornowski, and H. Weller, "Self-assembly of $\mathrm{ZnO}$ : from nanodots to nanorods," Angewandte Chemie International Edition, vol. 41, pp. 1188-1191, 2002.

[20] B. Wen, Y. Huang, and J. J. Boland, "Controllable growth of $\mathrm{ZnO}$ nanostructures by a simple solvothermal process," Journal of Physical Chemistry C, vol. 112, no. 1, pp. 106-111, 2008.

[21] J. Safaei-Ghomi and A. M. Ghasemzadeh, "Zinc oxide nanoparticles: a highly efficient and readily recyclable catalyst for the synthesis of xanthenes," Chinese Chemical Letters, vol. 23, pp. 1225-1229, 2012.

[22] L. Vayssieres, "Growth of arrayed nanorods and nanowires of $\mathrm{ZnO}$ from aqueous solutions," Advanced Materials, vol. 15, no. 5, pp. 464-466, 2003.

[23] L. E. Greene, B. D. Yuhas, M. Law, D. Zitoun, and P. Yang, "Solution-grown zinc oxide nanowires," Inorganic Chemistry, vol. 45, no. 19, pp. 7535-7543, 2006.

[24] X. Hou, F. Zhou, B. Yu, and W. Liu, "PEG-mediated synthesis of $\mathrm{ZnO}$ nanostructures at room temperature," Materials Letters, vol. 61, no. 11-12, pp. 2551-2555, 2007.

[25] H. Zhang, D. Yang, Y. Ji, X. Ma, J. Xu, and D. Que, "Low temperature synthesis of flowerlike $\mathrm{ZnO}$ nanostructures by cetyltrimethylammonium bromide-assisted hydrothermal process," Journal of Physical Chemistry B, vol. 108, no. 13, pp. 39553958, 2004.

[26] W. Z. Wang and G. H. Wang, "Synthesis and characterization of $\mathrm{Cu} 2 \mathrm{O}$ nanowires by a novel reduction route," Advanced Materials, vol. 14, pp. 67-69, 2002.

[27] J. Dobryszycki and S. Biallozor, "On some organic inhibitors of zinc corrosion in alkaline media," Corrosion Science, vol. 43, no. 7, pp. 1309-1319, 2001.

[28] Z. Li, Y. Xiong, and Y. Xie, "Selected-control synthesis of ZnO nanowires and nanorods via a PEG-assisted route," Inorganic Chemistry, vol. 42, no. 24, pp. 8105-8109, 2003.

[29] T. Sun, L. Feng, X. Gao, and L. Jiang, "Bioinspired surfaces with special wettability," Accounts of Chemical Research, vol. 38, no. 8, pp. 644-652, 2005. 

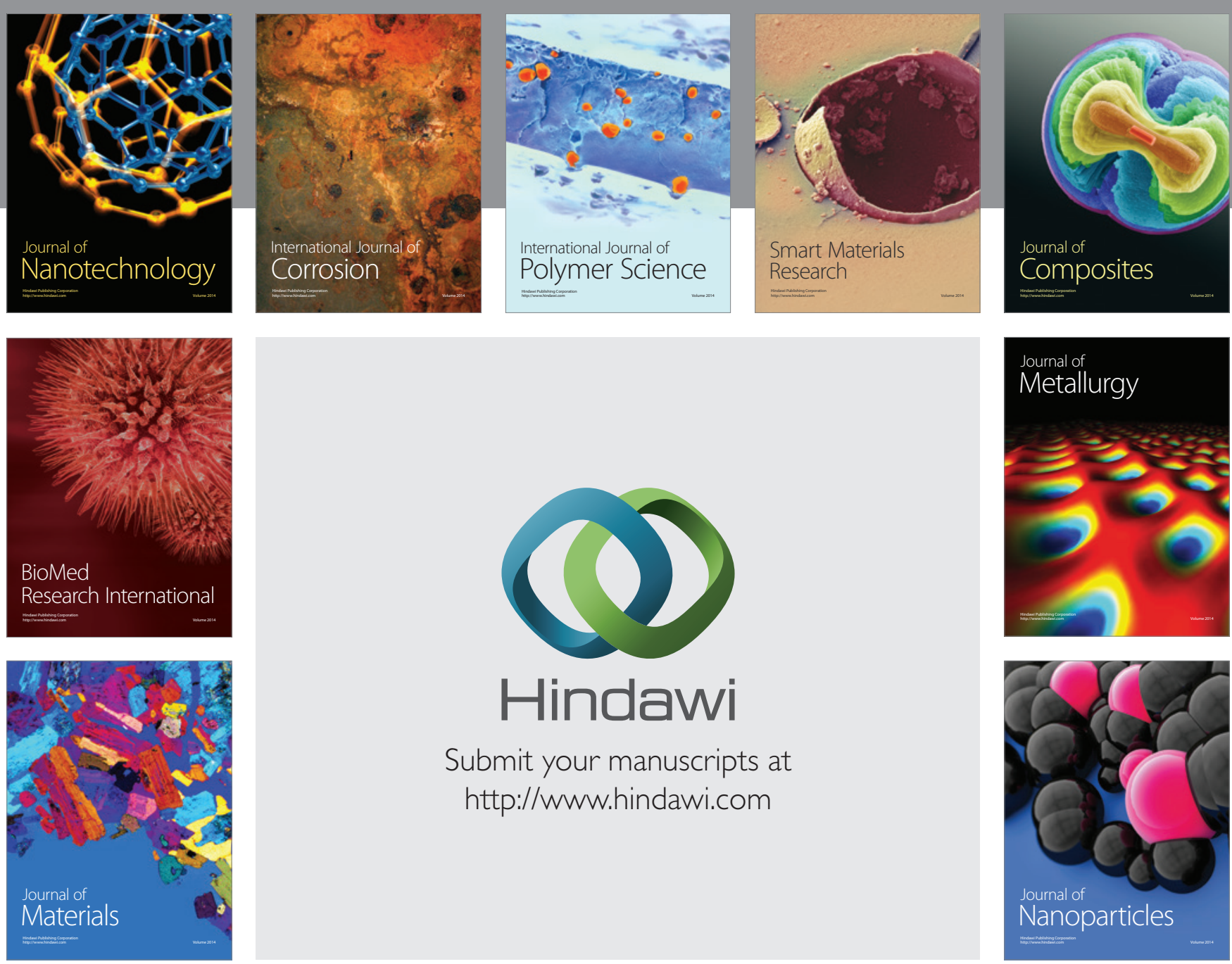

Submit your manuscripts at http://www.hindawi.com
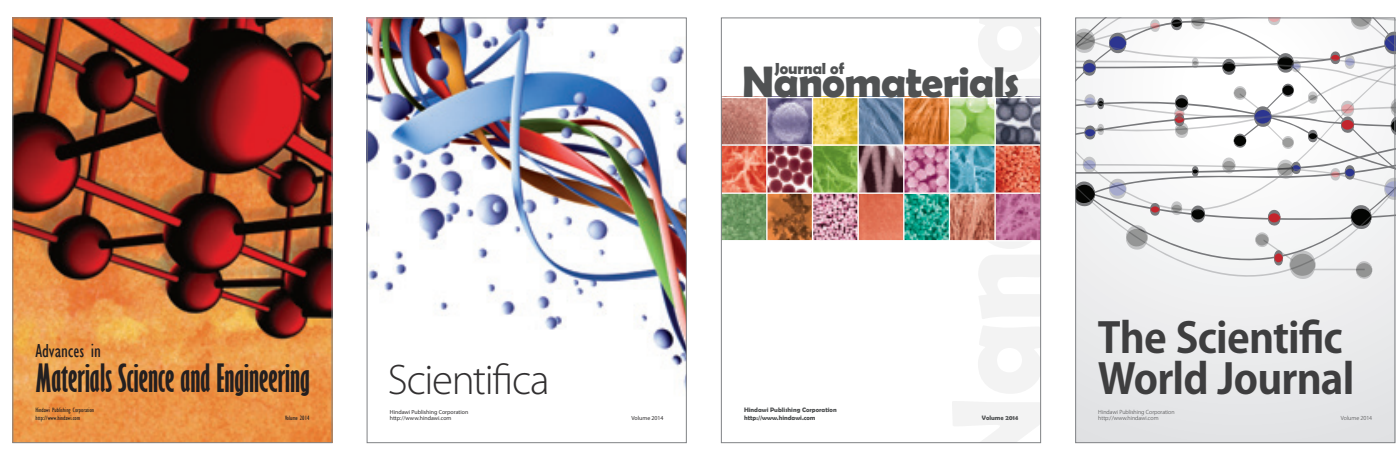

\section{The Scientific World Journal}
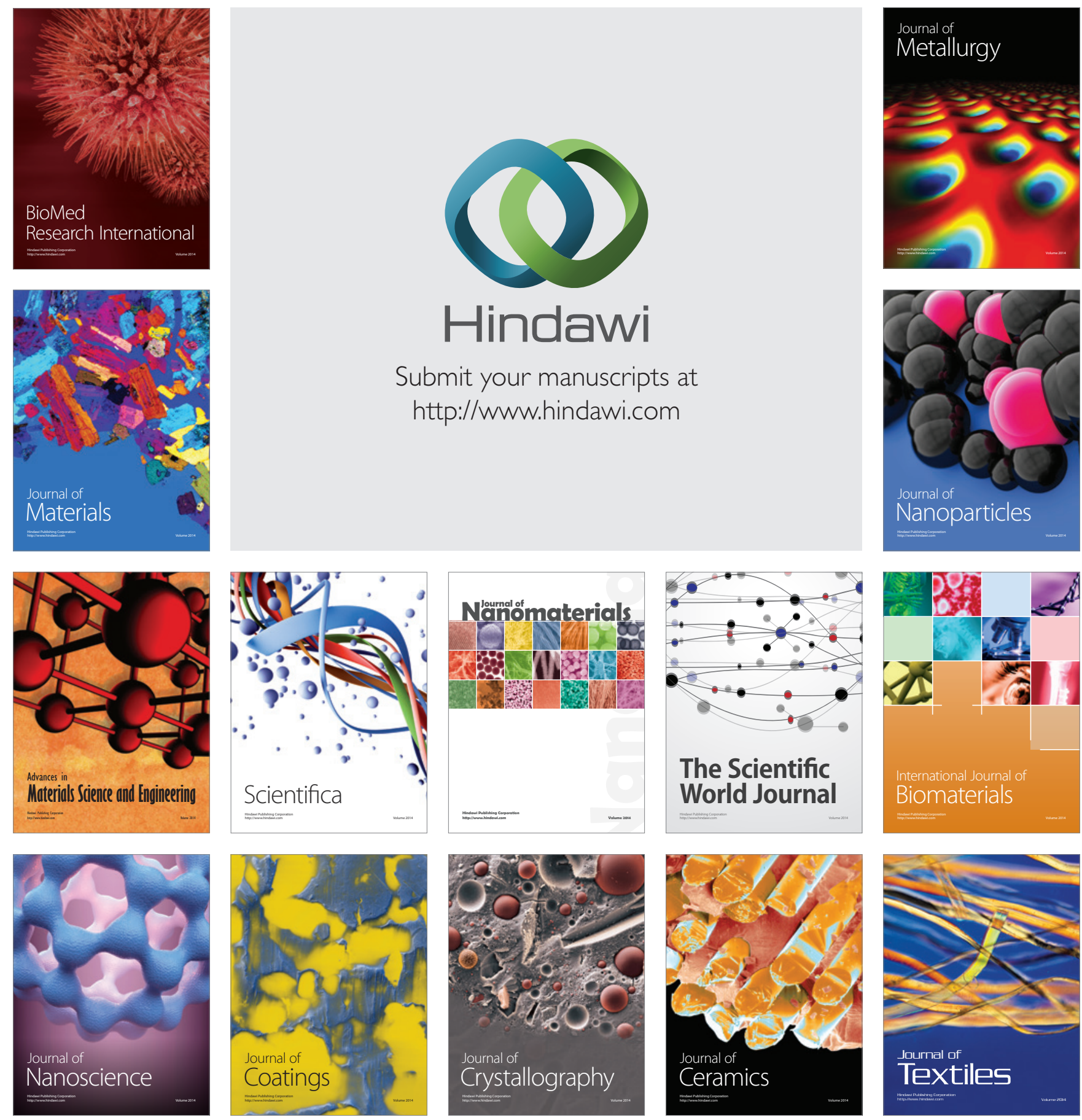